\title{
Investigation the effect of pyridine on the electrolysis of zinc from acidic and neutral solutions
}

\author{
(C) Alexander V. Kolesnikov, ${ }^{+}$and Irina V. Tsyganova \\ Chelyabinsk State University. Brothers St., Kashirinykh, 129. Chelyabinsk, 454001. Russia. \\ Phone: +7 (351) 794-25-12. E-mail: avkzinc@csu.ru
}

\begin{abstract}
*Supervising author; ${ }^{+}$Corresponding author
Keywords: electrolysis, zinc, cathodic processes, sulfuric acid, electrolyte, discharge currents, exchange currents, transfer numbers.
\end{abstract}

\begin{abstract}
The particular importance for the practice of zinc electrolysis is the knowledge of the reasons that affect the performance of this process. Previously published data indicate about the negative effects on the zinc current efficiency, energy consumption, quality of the cathode deposit non-optimal composition of the mixture of surfactant: licorice bone glue, lignosulfonate, flocculants, ekstragentami-2-ethyl-hexyl phosphoric acid (D2EHPA) various car oils, kerosene, white spirit, polyacrylamide. Electrochemical studies were performed using three electrolytes of the following composition: $0.25 \mathrm{M} \mathrm{ZnSO}_{4}, 0.25 \mathrm{M} \mathrm{ZnSO}_{4}+48 \mathrm{~g} / \mathrm{H}_{2} \mathrm{SO}_{4} ; 0.25 \mathrm{M}$ $\mathrm{ZnSO}_{4}+18 \mathrm{~g} / 1 \mathrm{H}_{2} \mathrm{SO}_{4}$. Potentiostatic and galvanostatic studies were carried out on the potentiostat "Potentiostat P-30J com" by "Elins" using a three-electrode cell. The working electrode (cathode) is made of copper with an area of $0.1 \mathrm{~cm}^{2}$; the auxiliary electrode (anode) is made of a platinum plate with an area of $0.20 \mathrm{~cm}^{2}$, the reference electrode is silver chloride $(\mathrm{AgCl} / \mathrm{Ag})$. Measurements were carried out at room temperature under intensive stirring with a magnetic stirrer. Initially, before the removal of the experimental curves, zinc buildup at the cathode was carried out at a constant potential of $-1200 \mathrm{mV}(\mathrm{AgCl} / \mathrm{Ag})$ for $5 \mathrm{~min}$, using an electrolyte of $0.25 \mathrm{M} \mathrm{ZnSO}_{4}$. For potentiometric measurements, the results are presented by averaged data obtained for 30 seconds of electrolysis, and for galvanostatic measurements by 0.05 seconds from the beginning of electrolysis.

In this article, we consider the effect of pyridine additives on the discharge of cations from zinc sulfate electrolytes, including sulfuric acid. The ratio in one of the three electrolytes of zinc mass to the mass of sulfuric acid corresponded to the composition of industrial solutions directed to the electrolysis of zinc. It is shown that the increase in the content of acid in the electrolyte, the increase in the cathode potential and the discharge rate of cations increases with the addition of pyridine decreases. The increase in the discharge rate of cations at low pyridine additives of $0.1 \mathrm{mg} / \mathrm{l}$ for electrolytes of the composition: $0.25 \mathrm{M} \mathrm{ZnSO}_{4}$ and $0.25 \mathrm{M}$ $\mathrm{ZnSO}_{4}+18 \mathrm{~g} / 1 \mathrm{H}_{2} \mathrm{SO}_{4}$, and the decrease in discharge currents with the addition of $0.6 \mathrm{mg} / \mathrm{l}$ pyridine in the electrolysis of a solution containing $18 \mathrm{~g} / 1 \mathrm{H}_{2} \mathrm{SO}_{4}$, compared with electrolysis without additives, testified to the priority effect of pyridine on the discharge of hydrogen cations. In the work it is noted, when removing dependencies with pyridine additives at the final stage, an accelerated increase in overvoltage occurs, and without the addition, the increase slows down. This is explained by the fact that the addition of pyridine, due to its ability to protonation and absorption of a significant amount of hydrogen, slows down the discharge of hydrogen to a greater extent than zinc in areas of high current density.

It is shown that the final parts of the curves of the voltammograms, the current sharing at high cathodic potentials increased almost nine-fold when the concentration of the pyridine up to $0.3 \mathrm{mg} / 1$ However, when the concentration of the pyridine up to $0.6 \mathrm{mg} / \mathrm{l}$ current sharing $\left(i_{o}\right)$, as well as the rate of discharge of ions decreases, which is consistent with the equation of Butler-Folmer for the cathodic process at high voltages.

The calculation of transport numbers has allowed concluding that at low transport numbers associated with the addition of pyridine, the function of the transition state Gibbs will increase, and the cation will be slower to approach the electrode because of the increased overvoltage. In this case, it is believed that the recovery reaction proceeds in the non-activation mode.
\end{abstract}

\section{References}

[1] A.V. Kolesnikov. Studies of reasons for the effective use of lignosulfonates in the electrolysis of zinc. Butlerov Communications. 2014. Vol.40. No.12. P.110-116. ROI: jbc-02/14-40-12-110 
INVESTIGATION THE EFFECT OF PYRIDINE ON THE ELECTROLYSIS OF ZINC FROM ACIDIC... $60-67$

[2] A.V. Kolesnikov. The electroreduction are investigated zinc from the background solution of sodium sulfate in the presence of cationic and anionic flocculants. Butlerov Communications. 2017. Vol.49. No.2. P.130-136. DOI: 10.37952/ROI-jbc-01/17-49-2-130

[3] A.V. Kolesnikov. The effect of flocculants on the electroreduction of zinc from sulphate solutions. Bulletin of the Saratov State Technical University "Chemistry and Chemical Technologies". 2014. No.3(76). P.47-52. (russian)

[4] A.V. Kolesnikov, L.A. Kazanbaev, P.A. Kozlov. The effect of organic substances on the processes of cementation and electrolysis of zinc. Non-ferrous metals. 2006. No.8. P.24-28. (russian)

[5] Alexander V. Kolesnikov. Investigations of the influence of di-2-ethyl-hexyl phosphoric acid on the parameters of electrolysis of zinc from acidic solutions. Butlerov Communications. 2018. Vol.55. No.8. P.127-133. DOI: 10.37952/ROI-jbc-01/18-55-8-127

[6] A.V. Kolesnikov, P.A. Kozlov, and I.M. Fominykh. Investigations of the influence of white spirit on the parameters of electrolysis of zinc from acidic solutions. Butlerov Communications. 2018. Vol.55. No.8. P.120-126. DOI: 10.37952/ROI-jbc-01/18-55-8-120

[7] V.D. Grigoriev, N.I. Fullman. The influence of polyacrylamide on the performance of electrolysis of zinc. Non-ferrous metals. 1976. No.5. P.24-25. (russian)

[8] V.D. Grigoriev, N.I. Fullman. The effect of pyridine on the yield of zinc at current. Non-ferrous metals. 1974. No.9. P.14-15. (russian)

[9] M.A. Abdeev, A.V. Kolesnikov, N.N. Ushakov. Wellawaya zinc-lead-containing materials. Moscow. 1985. P.111. (russian)

[10] A.P. Tomilov, S.G. Mayranovsky, M.Ya. Fioshin, V.A. Smirnov. Electrochemistry of organic compounds. Moscow. 1967. P.347. (russian)

[11] L.A. Kazanbaev, P.A. Kozlov, L.V. Kubasov, A.V. Kolesnikov. Hydrometallurgy of zinc (purification of solutions and electrolysis). Moscow. 2006. P.176. (russian)

[12] V.V. Skorchelletti. Theoretical electrochemistry. Leningrad. 1974. P.567. (russian)

[13] A.L. Rotinyan, K.I. Tikhonov, I.A. Shoshina. Theoretical electrochemistry. Moscow. 1974. P.552. (russian)

[14] P. Atkins. Physical chemistry. Vol. 2. Moscow. 1980. P.584. (russian) 